-Full Paper-

\title{
Expression of Hedgehog Family Genes in the Rat Uterus During Early Pregnancy
}

\author{
Kaiyu KUBOTA ${ }^{1)}$, Nobuhiko YAMAUCHI ${ }^{1)}$, Kenji MATSUMOTO ${ }^{1)}$, Ryo WATANABE ${ }^{1)}$, \\ Shinji OOZONO ${ }^{1)}$, Shinya ARAMAKI'), Chris WOOD ${ }^{2)}$, Tomoki SOH ${ }^{1)}$ and \\ Masa-Aki HATTORI') \\ ${ }^{1)}$ Department of Animal and Marine Bioresource Sciences, Graduate School of Agriculture, Kyushu University, Fukuoka \\ 812-8581, Japan and ${ }^{2)}$ Institute of Cell Biology and Genetics, College of Life Sciences, Zhejiang University, Zhejiang \\ 310058, China
}

\begin{abstract}
Hedgehog $(\mathrm{Hh})$ plays a pivotal role in various tissues during embryonic development, tissue homeostasis and tumorigenesis. In mammals, Hh exists in three homologs: Desert hedgehog (Dhh), Indian hedgehog (Ihh) and Sonic hedgehog $(S h h)$. In this study, we cloned full-length cDNAs encoding Dhh and Ihh from the rat uterus. Their amino acid sequences have a high homology with those of the mouse and human. In addition, the changes of Hh gene expression in the rat uterus during early pregnancy were analyzed. The results showed that all three hedgehog mRNAs were detected in the rat uterus at the proestrus stage and during early pregnancy $(1.5,3.5,5.5$ and 7.5 days post coitus: $\mathrm{dpc}$ ). Ihh mRNA expression varied and peaked at $3.5 \mathrm{dpc}$ in the luminal and glandular epithelium. Expression was decreased on $5.5 \mathrm{dpc}$ with the exception of sustained expression in the glandular epithelium. Despite such Ihh variability, the expressions of Dhh and Shh mRNA remained unchanged. This indicated that Ihh was mainly expressed in the rat uterus during early pregnancy. Moreover, the Hh target gene (glioma-associated oncogene homolog 1; Gli1) was also highly expressed at $3.5 \mathrm{dpc}$ in the epithelium and periepithelial stroma in a manner similar to the temporal pattern of Ihh expression. This suggests that Ihh signaling axis play a role in the rat uterus during early pregnancy. In summary, our results elucidate that Ihh is a predominant Hh protein in the rat uterus during early pregnancy and that other Hhs have the potential to be expressed. This observation will help to elucidate the basic molecular mechanism of rat uterus during early pregnancy.
\end{abstract}

Key words: Hedgehog, Implantation, Rat, Uterus

(J. Reprod. Dev. 54: 340-345, 2008)

$\mathbf{P}$ regnancy in mammals is accompanied by dramatic remodeling of uterine tissue, which provides optimal conditions for subsequent embryo implantation and development. In early pregnancy, the mammal's endometrial epithelial and stromal cells undergo rapid and coordinated proliferation and differentiation in response to steroid hormones, $17 \beta$-estradiol $\left(\mathrm{E}_{2}\right)$ and progesterone $\left(\mathrm{P}_{4}\right)[1$, $2]$. In rodents, $E_{2}$ stimulates epithelial cells to initiate proliferation on days 1 to 3 of pregnancy. Then $\mathrm{P}_{4}$, in combination with continuation of $E_{2}$ stimuli, triggers epithelial cell differentiation and stromal cell proliferation. By day 4 or 5 , the epithelial and stromal cells are tidily differentiated in final preparation for embryo attachment and implantation [3]. As a result, the endometrium acquires uterine receptivity, allowing for various reactions such as implantation and decidualization. However, in spite of all we know regarding the many aspects of the receptive uterus, the frequency of occurrence of female infertility begs a deeper understanding, particularly, of the details of hormonal control of the molecular and cellular mechanisms involved. These things remain unclear, in part, due to the nature of the intricate signaling hierarchy process and complex dynamics of subsequent morphological change. In addition, these signal axes have not only many steps but also con-

Accepted for publication: June 6, 2008

Published online in J-STAGE: July 8, 2008

Correspondence: N. Yamauchi (e-mail: ny0531@agr.kyushu-u.ac.jp) tain aspects of epithelial-stromal reciprocal interaction. Therefore, a stereoscopic viewpoint of cell-to-cell cross-talk is needed to address the molecular pathways required to prepare for the ability of the uterus to provide for successful implantation.

A progesterone receptor (Pgr), which is both a cognate receptor of $\mathrm{P}_{4}$ and a nuclear receptor, acts as a transcription factor to regulate target genes by binding to a specific ligand. This plays a pivotal role in remodeling of the uterus as a transducer of $\mathrm{P}_{4}$ action. Pgr knockout in mice causes a complete failure of decidualization [4]. Takamoto et al. [5] compared Pgr knockout mice with wildtype mice in an attempt to define not only the physiological phenotype but also the molecular pathways involved. They found that a gene known as Indian hedgehog (Ihh) was stimulated by $\mathrm{P}_{4}$ in the uterus. On day 3 of pseudopregnancy when the $\mathrm{P}_{4}$ level becomes high, Ihh mRNA expression rose in both the luminal and glandular epithelium. In addition, both the hedgehog $(\mathrm{Hh})$ receptor (patched 1; Ptc1) and a signal transducer of Hh (glioma-associated oncogene homolog 1; Gli1) were expressed in the epithelium and periepithelial stroma [6, 7]. These observations suggested that $\mathrm{P}_{4}$-responsive Ihh mediates intracellular communication between epithelial-stromal compartments in the pregnant uterus. Previously it was difficult to analyze the function of Ihh because ablation of Ihh was lethal to the embryo [8]. More recently, however, a conditional mutation of Ihh, which can eliminate Ihh just after the Pgr promoter switches on, has been used to inhibit embryo implantation 
Table 1. Sequences of the forward primers, reverse primers and probes used for real-time PCR

\begin{tabular}{llll}
\hline Gene & Forward (5'-3') & Reverse (5'-3') & Probe (5'-3') \\
\hline Dhh & cgtgtcggtcaaagctgat & agttccctcagccccttc & ggaggctg (\#75*) \\
Ihh & cccacgttcattgctctgt & aggaaagcagccacctgtc & ggtggctg (\#83) \\
Shh & ggaccgcagcaagtatgg & gccacggagttctctgct & tggctgtg (\#76) \\
Gli1 & ctggaggtctgcgtggtag & catggtgtctcagcgaagg & ccagggcc (\#81) \\
Hprt & gaccggttctgtcatgtcg & acctggttcatcatcactaatcac & agtcccag (\#95) \\
\hline
\end{tabular}

* Universal Probe Library probe number (Roche).

and decidualization [9]. In terms of its physiologic characteristics, this case is similar to that observed in earlier Pgr knockout mice [4]. This also confirmed Ihh as a major mediator of Pgr. Moreover, many downstream pathways of Ihh have been tested, but no notable factors have yet been discovered, and at present there remains little known regarding its downstream components.

Ihh is a member of the Hh family. Hh is a crucial morphogen of organogenesis and tumorigenesis [10]. It was first identified in Drosophila as a single gene and as a factor of segmentation. In mammals, there are three Hh homologs: the aforementioned Indian Hedgehog (Ihh), Desert hedgehog (Dhh) and Sonic hedgehog (Shh). Hh signaling is transmitted by two receptors, the twelvetransmembrane receptor Ptc and the seven-transmembrane receptor smoothened (Smo). Under the conditions of Hh binding to Ptc, Smo is released from the inhibitory action of Ptc. The signal-transducer of Hh protein, transcription factor Gli, is then translocated into the nucleus to regulate target gene transcription. This series of the Hh signaling pathway is wide-ranging through epithelial-mesenchymal communication resulting in cell proliferation, differentiation, apoptosis and migration. Unless $\mathrm{Hh}$ is expressed precisely, target cells become cancerous. Generally, Hh plays a role in various tissues during embryonic development. Ihh acts on osteogenesis and yolk sac formation $[11,12]$. Dhh maintains germ cell survival together with normal testicular and prostate development $[13,14]$. Finally Shh regulates left-right asymmetry, the polarity of limbs, foregut development, neuronal development and lung development [15-19]. Interestingly, Hh genes are expressed in a coordinated manner in some areas of reproductive organs including the prostate and ovaries [20]. However, there is not an obvious expression profile of the Hh family genes in the uterus with the exception of $I h h$.

The Hh family genes are the key regulators of the endometrium to achieve receptivity for implantation by mediating intracellular communication between epithelial-stromal compartments. The present study was performed to further investigate the expressions of the three Hh family genes in the rat uterus. We first confirmed the sequences of rat Ihh and Dhh cDNA because they have previously only been analyzed in silico. We then investigated the expressions of all three Hh mRNAs and the Hh target gene Gli1 by quantitative real-time PCR and in situ hybridization in the rat uterus during early pregnancy.

\section{Materials and Methods}

\section{Animals}

This research was conducted using Wistar strain rats raised in our own laboratory (Department of Animal and Marine Bioresource Sciences, Graduate School of Agriculture, Kyushu University). The rats were housed under temperature- and lightcontrolled conditions (lights on from 0800 to $2000 \mathrm{~h}$ ) with free access to food and water. The stages of the estrus cycles in each rat were determined by the vaginal smear method. Adult female rats were mated with males, and the day on which spermatozoa were found in the vaginal smear was designated 0.5 days post coitus (dpc). All experiments were conducted according to the Guidelines for the Care and Use of Laboratory Animals (Graduate School of Agriculture, Kyushu University) and with the approval of the Kyushu University Laboratory Animal Care and Use Committee.

\section{Sequence determination and motif search}

Rat $I h h$ and Dhh cDNA were amplified by specific primer sets from reverse transcribed uterine cDNA using an oligo (dT) primer or an inner sequences primer. Specific primer sets were designed by predicted sequences ( $\mathrm{hh}$, GenBank nucleotide sequence database genbank accession No. XM_001060415; Dhh, XM_001062733). After electrophoresis and extraction from agarose gel by MagExtractor -PCR \& Gel Clean up- (Toyobo, Tokyo, Japan) for each PCR product, amplicons were then subcloned into a pGEM-T Easy Vector (Promega, Madison, WI, USA). Sequencing was handled using a GenomeLab DTCS Quick Start Kit (Beckman Coulter, Fullerton, CA, USA) according to the manufacturer's protocol, followed by sequencing with a CEQ 8800 system (Beckman Coulter). An online signal peptide search, the signalP 3.0 server (http://www.cbs.dtu.dk/services/SignalP/), Motif search software, a NCBI Conserved Domain search (http://www.ncbi.nlm.nih.gov/ Structure/cdd/wrpsb.cgi) and ExPASy PROSITE (http:// www.expasy.ch/prosite/) were used for analysis of deduced amino acid sequences.

\section{RNA extraction, reverse transcription (RT) and quantitative real-time PCR}

Total RNA was extracted from homogenized uteri at the proestrus stage (P), 1.5, 3.5, 5.5 and $7.5 \mathrm{dpc}$ using a Sepasol-RNA I Super (Nacalai Tesque, Kyoto, Japan) with RQ1 RNase-Free DNase (Promega) treatment, according to the manufacturer's protocol. RNA quality was assessed by ethidium bromide agarose gel electrophoresis and spectrophotometric UV absorbance at 260/280 $\mathrm{nm}$. One microgram of each RNA sample was reverse transcribed with a Transcriptor First Strand cDNA Synthesis Kit (Roche, Mannheim, Germany) using an oligo-dT primer in a $20 \mu \mathrm{l}$ solution. Real-time PCR was carried out using a Roche Light Cycler 1.5 system (Roche). A Taqman Master kit (Roche) in combination with 

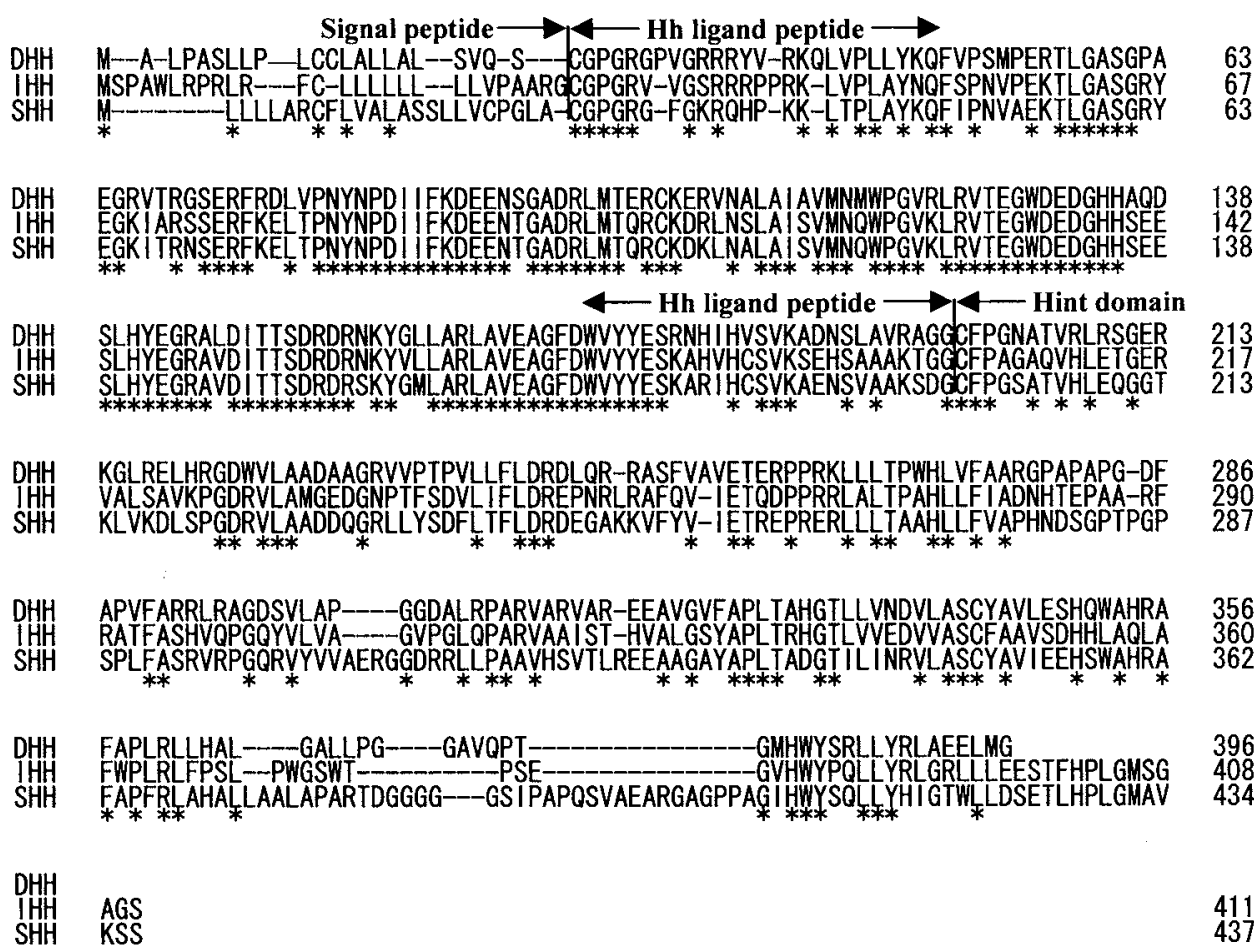

Fig. 1. Rat Hh family proteins. Rat IHH and DHH sequences were identified, and rat SHH sequence was cited from genbank (NM_017221). Amino acid residues are numbered on the right. Conserved amino acid residues are indicated by asterisks below the alignment. Hh proteins consist of a signal peptide, ligand peptide and Hint module. Rat hedgehog proteins are well conserved, especially in the ligand region.

each Universal ProbeLibrary probe (Roche) was used to assess mRNA expression. Specific PCR primers and probes for Ihh (XM_001060415), Dhh (XM_001062733), Shh (NM_017221), Gli1 (XM_001056128) and hypoxanthine guanine phosphoribosyl transferase (Hprt, NM_012583) were designed using the Probe Library Assay Design Center (http://www.roche-appliedscience.com/sis/rtpcr/upl/). The primers and probes are shown in Table 1 . The PCR cycle parameters were an initial denaturation step at $95 \mathrm{C}$ for $10 \mathrm{~min}, 45$ cycles at $95 \mathrm{C}$ for $10 \mathrm{sec}$ and $60 \mathrm{C}$ for 25 sec. Hprt served as an internal control and was used to normalize for differences in each sample.

\section{In situ hybridization on tissue section}

Ihh, Dhh, Shh and Gli1 PCR products were each subcloned into a pGEM-T Easy Vector. Their antisense and sense RNA probes were synthesized using PCR-amplified templates and RNA polymerase promoter sequences. Digoxigenin (DIG)-labeled antisense and sense RNA probes were prepared with T7 or SP6 RNA polymerase using a DIG RNA Labeling Mix kit (Roche). Cryosections (10 $\mu \mathrm{m}$ thick) of the uterus at each stage were processed in OCT compound (Sakura Finetechnical, Tokyo, Japan) and fixed with $4 \%$ (w/v) paraformaldehyde. After washing with PBS, the sections were acetylated in $0.1 \mathrm{M}$ triethanolamine containing $0.25 \%(\mathrm{v} / \mathrm{v})$ acetic anhydride. They were then hybridized with cRNA probes in $3 \times$ SSC containing $50 \%(\mathrm{v} / \mathrm{v})$ formamide, $125 \mu \mathrm{g} / \mathrm{ml}$ yeast RNA,
$100 \mu \mathrm{g} / \mathrm{ml}$ salmon sperm, $10 \%$ (w/v) dextran sulfate, $1 \times$ Denhardt solution and $0.12 \mathrm{M}$ phosphate at $60 \mathrm{C}$ overnight. The next day, the sections were serially washed at $42 \mathrm{C}$ with post-hybridization solution, i.e., $5 \times$ SSC and $2 \times$ SSC containing $50 \%$ formamide. They were then washed with $2 \times$ SSC, $0.2 \times$ SSC and $100 \mathrm{mM}$ Tris-HCl (pH 7.5) containing $150 \mathrm{mM} \mathrm{NaCl}$ and $0.01 \%(\mathrm{v} / \mathrm{v})$ Tween 20 , treated for $60 \mathrm{~min}$ with $1.5 \%(\mathrm{w} / \mathrm{v})$ blocking reagent (Roche) and incubated with anti-DIG antibody conjugated with alkaline phosphatase at $4 \mathrm{C}$ overnight. The next day, the sections were washed twice with $100 \mathrm{mM}$ Tris- $\mathrm{HCl}$ (pH 7.5) containing $150 \mathrm{mM} \mathrm{NaCl}$ and $0.01 \%(\mathrm{v} / \mathrm{v})$ Tween 20 and they washed with $100 \mathrm{mM}$ Tris- $\mathrm{HCl}$ (pH 9.5) containing $100 \mathrm{mM} \mathrm{NaCl}$ and $50 \mathrm{mM} \mathrm{MgCl}$. A subsequent enzyme-catalyzed color reaction with BCIP/NBT produced an insoluble blue precipitate. After color development, the sections were washed with $6 \mathrm{mM}$ Tris- $\mathrm{HCl}(\mathrm{pH} 8.0)$ containing $0.6 \mathrm{mM}$ EDTA and were observed for color reaction under a microscope.

\section{Statistical analysis}

Each experiment was repeated three times. The results are expressed as a ratio against the proestrus stage and are expressed as means \pm SEM. Values were analyzed by ANOVA followed by the Student-Newman-Keuls test using StatView (Abacus Concepts, Berkeley, CA, USA). Differences were considered significant at the level of $\mathrm{P}<0.05$. 
A
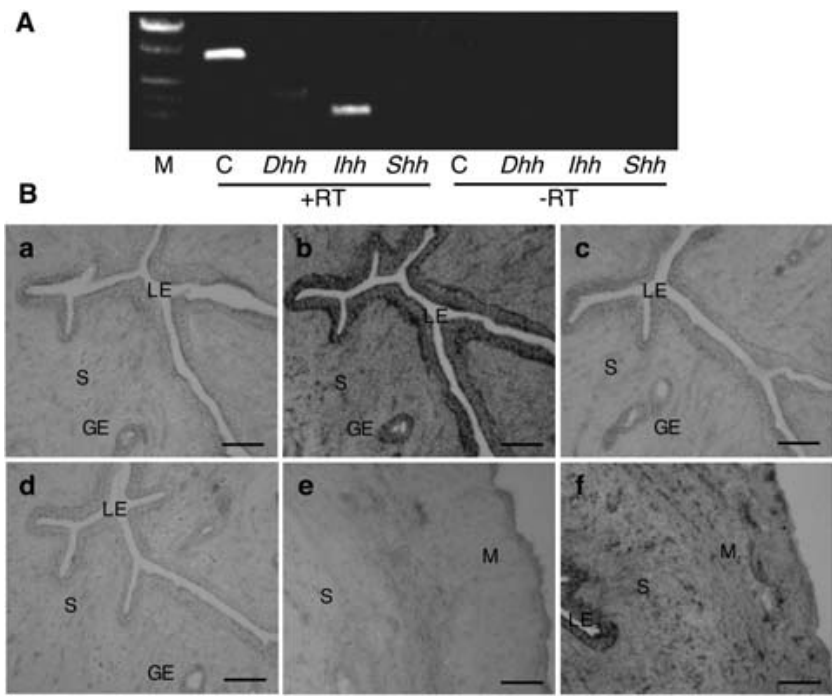

Fig. 2. Expressions of $\mathrm{Hh}$ genes in the rat uterus. A) Expression analysis of three Hh mRNAs as detected by RT-PCR. Total RNA was extracted from the rat uterus at 3.5 dpc. $\beta$-actin was used as an internal control. PCR was conducted using firststrand cDNA samples with $(+)$ and without $(-)$ RT. Lane M, DNA molecular weight standard; lane C, $\beta$-actin. B) In situ hybridization analysis of Hh mRNA expressions in the rat uterus at 3.5 dpc. Sections were hybridized with each probe. The hybridization signals were then detected using an antidigoxigenin alkaline phosphatase conjugate (a and e, antisense Dhh; b and f, antisense $I h h ;$ c, antisense $S h h$; d, sense $I h h$ ). GE, glandular epithelium; LE, luminal epithelium; S, stroma; M, myometrium. The scale bars represent $100 \mu \mathrm{m}$.

\section{Results}

\section{Rat $\mathrm{IHH}$ and $\mathrm{DHH}$}

Rat Ihh and Dhh cDNA were amplified by RT-PCR using specific primers designed from predicted sequences. The deduced amino acid sequences of IHH, DHH and SHH had also a high degree of similarity, particularly in the Hh signaling ligand peptide region (Fig.1). The Hh peptides consisted of an $\mathrm{N}$-terminus signal peptide, ligand peptide and Hint module. Furthermore, the deduced amino acid sequences were highly homologous to the orthologs of mouse and human. Rat IHH shared $97 \%$ and $94 \%$ homology with mouse and human IHH, respectively. Likewise, rat DHH shared 100 and 97\% homology with mouse and human DHH, respectively. Hh homologs were conserved well except for slight c-terminus diverseness.

\section{Temporal expression of Hh genes in the rat uterus}

To examine which Hh mRNAs are expressed in the rat uterus, we analyzed the expression of rat Hh mRNAs by RT-PCR (Fig. 2A). As expected, a strong signal of Ihh mRNA was detected in the uterus on $3.5 \mathrm{dpc}$. In addition, a weak signal of Dhh mRNA was detected, and Shh mRNA was barely detectable. Furthermore, only Ihh mRNA was detected in the luminal and glandular epithelium by in situ hybridization, and $D h h$ and Shh were not detected in the endometrium (Fig. 2Ba-d). Hh mRNAs were not detected by in

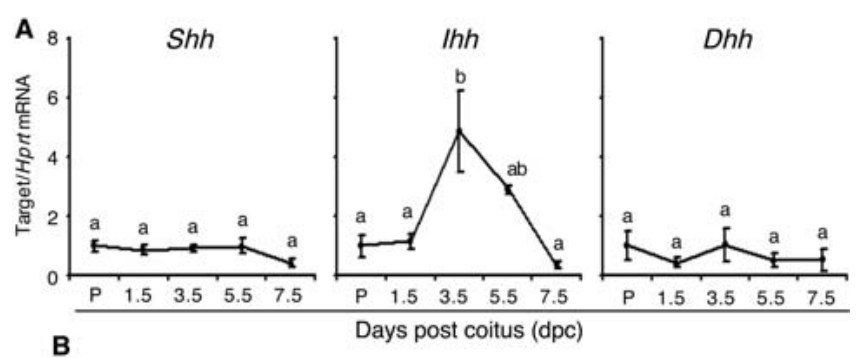

B

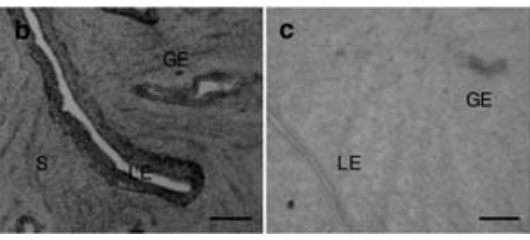

Fig. 3. Expression profiles of Hh genes in the rat uterus during early pregnancy. A) Changes in the expressions of Hh mRNAs analyzed by quantitative real-time PCR. Total RNA was extracted from the rat uterus at the proestrus stage $(\mathrm{P})$ and at 1.5, 3.5, 5.5 and 7.5 dpc. Hprt was used as an internal control. The results are expressed as a ratio against the proestrus stage and are expressed as means \pm SE $(n=3)$. Values with different superscripts are significantly different $(\mathrm{P}<0.05)$. B) In situ hybridization analysis of $I h h$ mRNA expression in the rat endometrium during early pregnency (a, $1.5 \mathrm{dpc}$; b, $3.5 \mathrm{dpc}$; c, 5.5 dpc). Sections were hybridized with Ihh probe. The hybridization signals were then detected using an antidigoxigenin alkaline phosphatase conjugate. GE, glandular epithelium; LE, luminal epithelium; S, stroma. The scale bars represent $100 \mu \mathrm{m}$.

situ hybridization in the myometrium of the rat uterus (Fig. 2Be and f). The changes in Hh mRNA expression during early pregnancy were analyzed by real-time PCR (Fig. 3A). In this study, all three mRNAs were detected in the rat uterus. Ihh mRNA expression in the $3.5 \mathrm{dpc}$ uterus was particularly increased with about 5-fold higher expression than that in the $1.5 \mathrm{dpc}$ uterus. The expression of Ihh mRNA decreased gradually to the same basal level as the proestrus stage at $7.5 \mathrm{dpc}$. On the other hand, the expressions of Dhh and Shh mRNAs did not change from the non-pregnant stage, proestrus cycle, through to $7.5 \mathrm{dpc}$. In situ hybridization analysis also showed a transient increase of Ihh mRNA expression during early pregnancy (Fig. 3B). No Ihh mRNA signal was detected in the epithelium or stroma at $1.5 \mathrm{dpc}$. However, a strong signal of I hh mRNA was apparent in both the luminal epithelium and glandular epithelium on $3.5 \mathrm{dpc}$. On $5.5 \mathrm{dpc}$, expression was decreased in the luminal epithelium, but expression remained in the glandular epithelium.

\section{Expression of Gli1 gene during early pregnancy}

Although Ihh mRNA was expressed in the luminal epithelium, expression downstream of Hh remained unclear. Therfore, we analyzed the expression of the Hh target gene Gli1 by real-time PCR (Fig. 4A). Gli1 mRNA was highly expressed on $3.5 \mathrm{dpc}$ (at a level approximately 6 -fold higher than that of the proestrus stage) and then decreased completely on $7.5 \mathrm{dpc}$ in a manner similar to the 
A

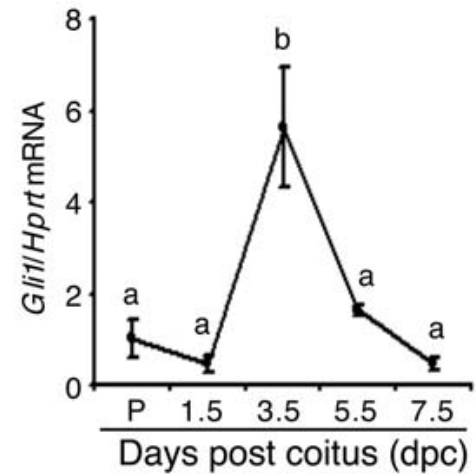

B
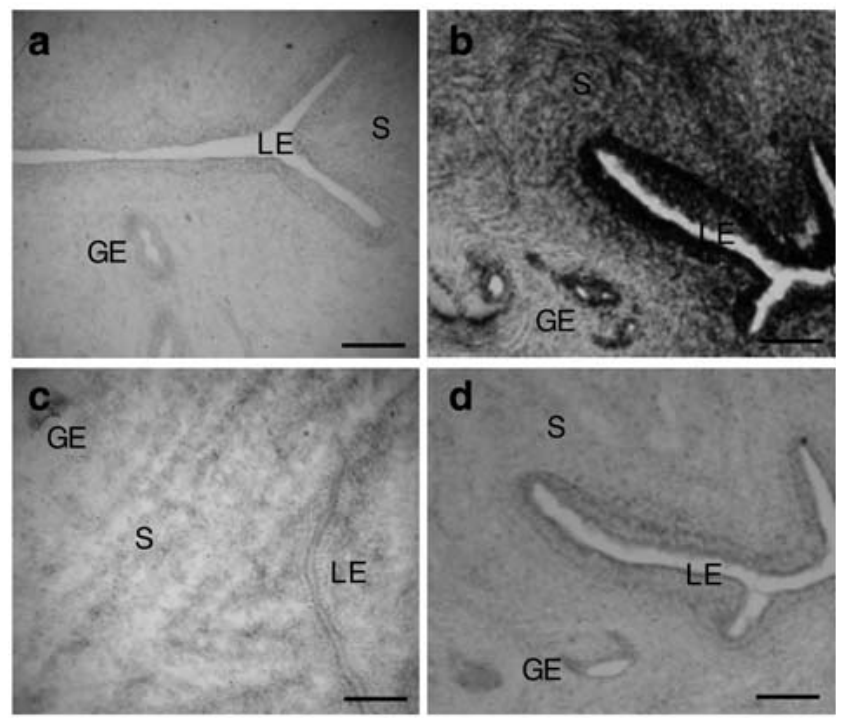

Fig. 4. Expression profile of the Gli1 gene in the rat uterus during early pregnancy. A) Change in the expression of Gli1 mRNA analyzed by quantitative real-time PCR. Total RNA was extracted from the rat uterus at the proestrus stage $(\mathrm{P})$ and at 1.5, 3.5, 5.5 and 7.5 dpc. Hprt was used as an internal control. The results are expressed as a ratio against the proestrus stage and are expressed as means \pm SE $(n=3)$. Values with different superscripts are significantly different $(\mathrm{P}<0.05)$. B) In situ hybridization analysis of Gli1 mRNA expression in the rat endometrium during early pregnancy (a, $1.5 \mathrm{dpc}$; $\mathrm{b}$ and d, 3.5 dpc; c, $5.5 \mathrm{dpc}$ ). The sections were hybridized with a sense (d) or antisense (a, b, c) Gli1 probe. The hybridization signals were then detected using an anti-digoxigenin alkaline phosphatase conjugate. GE, glandular epithelium; LE, luminal epithelium; S, stroma. The scale bars represent $100 \mu \mathrm{m}$.

temporal pattern of Ihh expression. Furthermore, expression of the Gli1 mRNA was observed in the epithelium and periepithelial stroma of the endometrium (Fig. 4B). However, Gli1 mRNA was only weakly detected in the stroma distant from the epithelium.

\section{Discussion}

Hh essentially functions in various processes during embryonic development and tumorigenesis. Dysregulation of Hh signaling leads to a number of critical human disorders. Shh mutation has been reported in the case of holoprosencephaly and cardiovascular disease [21, 22]. Hh also controls not only embryonic development but also homeostasis in the adult gut [23]. In addition, overexpression of Hh signaling results in cancer [24]. During the gestation period, it has been reported that Hh signaling plays an important role in the mouse endometrium through epithelial-stroma crosstalk, resulting in tissue remodeling of the uterus. In the present study, we demonstrated that Hh mRNAs are expressed in the rat uterus. In particular, transient expression of Ihh mRNA was observed in the $3.5 \mathrm{dpc}$ uterus. These results are the first findings concerning Hh gene expressions in the uterus of pregnant rats and reflect those of previous reports in the mouse and hamster [5, 6, 25]; they also imply that Hh may play a significant role in mammals during the implantation phase.

In mammals, the Hh family includes $I h h, D h h$ and Shh. Despite the importance of Hh signaling, rat $I h h$ and Dhh has only been analyzed in silico [26]. In postgenomic analysis, computer analysis is useful to determine orthologs and expression in tissues by EST. In silico analysis is highly capable of detecting exon-intron boundaries. Moreover, it can be used to evaluate both the transcription and translation starting positions and their stop positions. However, the entire sequences of rat $I h h$ and Dhh cDNA had not yet been identified. Therefore, the sequences were precisely confirmed in this study. Our results and previous reports show that Hh proteins consist of a signal peptide, ligand peptide and Hint module. In general, the Hh peptide is translated as an immature precursor [27]. The Hh precursor enters the secretion pathway with cleavage of a signal peptide. The autoprocessing reaction is subsequently achieved through catalyzation and mediation of a Hint module to cholesterol, followed by palmitoylation of the N-terminus. Finally, the fully-processed Hh lignd peptide is secreted from the producing cell. Rat IHH, DHH and SHH are all highly similar and well conserved, although their tissue distributions differ. Small differences include SHH being slightly longer in terms of its Hint module and the existence of an HPLGMXXXXS motif in its C-terminus; these differences, together with those of $\mathrm{IHH}$, might contribute to the diverseness of tissue distribution. Such diversity, however, is clearly not attributed to these differences alone. Analysis of the 5'UTR promoter and 3'-UTR regions is important for understanding the mechanism of tissue distribution.

Interestingly, Hh has a significant effect in reproductive organs. For example, Hh signaling regulates not only organogenesis but also germ cell survival in the testis [13]. In addition, three $\mathrm{Hh}$ genes are co-expressed in the ovaries, and both $\mathrm{Ihh}$ and Dhh gene expression levels change dynamically [20]. Hh gene expression in the pregnant rat uterus has not been reported with the exception of Ihh. In the present study, the expression patterns of three $\mathrm{Hh}$ ligands were analyzed by real-time PCR. Not only Ihh mRNA expression, but also Dhh and Shh mRNA expressions, were detected in the uterus. However, the behavior of the expressions remained constant and did not fluctuate with the exception of Ihh. Furthermore, in situ hybridization analysis did not detect any signals with the Dhh and Shh probes. These results suggest that $I h h$ is mainly expressed in the rat uterus during early pregnancy and that the expression levels of Dhh and Shh mRNAs might be at a low 
level and not induced by factors of pregnancy, including $\mathrm{P}_{4}$ and $\mathrm{E}_{2}$. Although their expressions might be low in the uterus at the proestrus stage or during early pregnancy, the potential roles of Dhh and Shh remain unclear.

In mice, Ihh mediates tissue remodeling in the pregnant uterus by the action of $\mathrm{P}_{4}[5-7,9]$. In this study, quantitative analysis of Hh mRNA expression was conducted in the rat uterus. Similar to the reports in mice, Ihh mRNA was expressed in the luminal and glandular epithelium on $3.5 \mathrm{dpc}$ and in the glandular epithelium on 5.5 dpc. The stage expressing Ihh mRNA corresponded with the dpc which, in turn, was correlated with increases in the $\mathrm{P}_{4}$ level. Our quantitative results show that Ihh mRNA expression was high on $3.5 \mathrm{dpc}$, indicating that $\mathrm{Ihh}$ gene expression is only induced by $\mathrm{P}_{4}$-signaling and is not induced by copulation stimuli or embryonic attachment. In spite of the high $\mathrm{P}_{4}$ level maintained from 3.5 to 7.5 dpc, expression of Ihh mRNA was transient and was decreased at $7.5 \mathrm{dpc}$. This may be due to the action of $\mathrm{E}_{2}$ on $3.5 \mathrm{dpc}$. Ovariectomized mice treated with both $\mathrm{P}_{4}$ and $\mathrm{E}_{2}$ show no expression of Ihh gene [6]. Wakitani et al. [28] reported that leukemia inhibitory factor ( $\mathrm{Lif}$ ) can induce Ihh expression during the implantation period. As Lif is induced by $\mathrm{E}_{2}$, the tissue remodeling of the uterus mediated by $I h h$ must include the involvement of not only $\mathrm{P}_{4}$ but also $\mathrm{E}_{2}$. More investigation is needed to elucidate this concept.

In the present study, the expression of Gli1 mRNA, one of the target genes of $\mathrm{Hh}$, was analyzed in the rat uterus. The Gli family consists of three homologs in mammals, and it has been reported that the Gli1 is transiently and synchronously expressed together with Ihh during early pregnancy in the mouse endometrium [6]. Our results in the rat uterus support the reports in the mouse. Gli1 mRNA was expressed in the epithelium and periepithelial stroma. Little is known about the target genes of the transcription factor Gli1 after translocation into the nucleus. To elucidate the function of Ihh during early pregnancy, further studies are required to investigate the relation between Gli1 and endomatrial decidualization.

In conclusion, Hh genes were expressed in the rat uterus during the uterine remodeling period. Ihh acts as a mediator of the $\mathrm{P}_{4}$ dependent action of the endometrium in both mice and hamsters and may play a crucial role in beginning reconstruction of the uterus to prepare for embryo implantation, not only in rodents but also in other mammalian species [5, 6, 9, 25]. Understanding and controlling the Hh signaling pathway in the uterus may improve the fecundity rate of animal production and in turn lead to benefits in human reproductive health.

\section{Acknowledgements}

This research was supported by a Grant-in-Aid for Scientific Research (C) from the Japan Society for the Promotion of Science (No. 18580282) to N. Y..

\section{References}

1. Carson DD, Bagchi I, Dey SK, Enders AC, Fazleabas AT, Lessey BA, Yoshinaga K. Embryo implantation. Dev Biol 2000; 223: 217-237.

2. Stewart CL, Cullinan EB. Preimplantation development of the mammalian embryo and its regulation by growth factors. Dev Genet 1997; 21: 91-101.

3. Wang H, Dey SK. Roadmap to embryo implantation: clues from mouse models. Nat
Rev Genet 2006; 7: 185-199.

4. Lydon JP, DeMayo FJ, Funk CR, Mani SK, Hughes AR, Montgomery CA, Jr, Shyamala G, Conneely OM, O'Malley BW. Mice lacking progesterone receptor exhibit pleiotropic reproductive abnormalities. Genes Dev 1995; 9: 2266-2278.

5. Takamoto N, Zhao B, Tsai SY, DeMayo FJ. Identification of Indian hedgehog as a progesterone-responsive gene in the murine uterus. Mol Endocrinol 2002; 16: 2338 2348.

6. Matsumoto H, Zhao X, Das SK, Hogan BL, Dey SK. Indian hedgehog as a progesterone-responsive factor mediating epithelial-mesenchymal interactions in the mouse uterus. Dev Biol 2002; 245: 280-290.

7. Paria BC, Ma W, Tan J, Raja S, Das SK, Dey SK, Hogan BL. Cellular and molecula responses of the uterus to embryo implantation can be elicited by locally applied growth factors. Proc Natl Acad Sci USA 2001; 98: 1047-1052.

8. St-Jacques B, Hammerschmidt M, McMahon AP. Indian hedgehog signaling regulates proliferation and differentiation of chondrocytes and is essential for bone formation. Genes Dev 1999; 13: 2072-2086.

9. Lee K, Jeong J, Kwak I, Yu CT, Lanske B, Soegiarto DW, Toftgard R, Tsai MJ, Tsai $\mathrm{S}$, Lydon JP, DeMayo FJ. Indian hedgehog is a major mediator of progesterone signaling in the mouse uterus. Nat Genet 2006; 38: 1204-1209.

10. Ingham PW, McMahon AP. Hedgehog signaling in animal development: paradigms and principles. Genes Dev 2001; 15: 3059-3087.

11. Pathi S, Pagan-Westphal S, Baker DP, Garber EA, Rayhorn P, Bumcrot D, Tabin CJ Blake Pepinsky R, Williams KP. Comparative biological responses to human Sonic, Indian, and Desert hedgehog. Mech Dev 2001; 106: 107-117.

12. Byrd N, Becker S, Maye P, Narasimhaiah R, St-Jacques B, Zhang X, McMahon J McMahon A, Grabel L. Hedgehog is required for murine yolk sac angiogenesis. Development 2002; 129: 361-372.

13. Bitgood MJ, Shen L, McMahon AP. Sertoli cell signaling by Desert hedgehog regulates the male germline. Curr Biol 1996; 6: 298-304.

14. Fan J, Akabane H, Zheng X, Zhou X, Zhang L, Liu Q, Zhang YL, Yang J, Zhu GZ Male germ cell-specific expression of a novel Patched-domain containing gene Ptchd3. Biochem Biophys Res Commun 2007; 363: 757-761.

15. Tsukui T, Capdevila J, Tamura K, Ruiz-Lozano P, Rodriguez-Esteban C, YoneiTamura S, Magallon J, Chandraratna RA, Chien K, Blumberg B, Evans RM, Belmonte JC. Multiple left-right asymmetry defects in Shh (-/-) mutant mice unveil a convergence of the shh and retinoic acid pathways in the control of Lefty-1. Proc Nat Acad Sci USA 1999; 96: 11376-11381.

16. Johnson RL, Riddle RD, Laufer E, Tabin C. Sonic hedgehog: a key mediator of anterior-posterior patterning of the limb and dorso-ventral patterning of axial embryonic structures. Biochem Soc Trans 1994; 22: 569-574.

17. Litingtung $\mathbf{Y}$, Lei L, Westphal $\mathbf{H}$, Chiang $\mathrm{C}$. Sonic hedgehog is essential to foregut development. Nat Genet 1998; 20: 58-61.

18. Roelink H, Augsburger A, Heemskerk J, Korzh V, Norlin S, Ruiz i Altaba A Tanabe Y, Placzek M, Edlund T, Jessell TM, Dodd J. Floor plate and motor neuron induction by vhh-1, a vertebrate homolog of hedgehog expressed by the notochord. Cell 1994; 76: 761-775.

19. Bellusci S, Furuta Y, Rush MG, Henderson R, Winnier G, Hogan BL. Involvement of Sonic hedgehog (Shh) in mouse embryonic lung growth and morphogenesis. Development 1997; 124: 53-63.

20. Russell MC, Cowan RG, Harman RM, Walker AL, Quirk SM. The hedgehog signaling pathway in the mouse ovary. Biol Reprod 2007; 77: 226-236.

21. Nanni L, Ming JE, Du Y, Hall RK, Aldred M, Bankier A, Muenke M. SHH mutation is associated with solitary median maxillary central incisor: a study of 13 patients and review of the literature. Am J Med Genet 2001; 102: 1-10.

22. Bijlsma MF, Peppelenbosch MP, Spek CA. Hedgehog morphogen in cardiovascular disease. Circulation 2006; 114: 1985-1991.

23. van den Brink GR, Hardwick JC, Tytgat GN, Brink MA, Ten Kate FJ, Van Deventer SJ, Peppelenbosch MP. Sonic hedgehog regulates gastric gland morphogenesis in man and mouse. Gastroenterology 2001; 121: 317-328.

24. Taipale J, Beachy PA. The Hedgehog and Wnt signalling pathways in cancer. Nature 2001; 411: 349-354.

25. Khatua A, Wang X, Ding T, Zhang Q, Reese J, DeMayo FJ, Paria BC. Indian hedgehog, but not histidine decarboxylase or amphiregulin, is a progesterone-regulated uterine gene in hamsters. Endocrinology 2006; 147: 4079-4092

26. Katoh $\mathbf{Y}$, Katoh M. Identification and characterization of rat Desert hedgehog and Indian hedgehog genes in silico. Int J Oncol 2005; 26: 545-549.

27. Mann RK, Beachy PA. Novel lipid modifications of secreted protein signals. Annu Rev Biochem 2004; 73: 891-923.

28. Wakitani S, Hondo E, Phichitraslip T, Stewart CL, Kiso Y. Upregulation of Indian hedgehog gene in the uterine epithelium by leukemia inhibitory factor during mouse implantation. J Reprod Dev 2008; 54: 113-116. 